\title{
CARBONO DO SOLO E A MITIGAÇÃO DA MUDANÇA CLIMÁTICA GLOBAL ${ }^{\#}$
}

\author{
Pedro L. O. de A. Machado*
}

Embrapa Solos, Rua Jardim Botânico, 1024, 22460-000 Rio de Janeiro - RJ

Recebido em 25/6/04; publicado na web em 14/1/05

\begin{abstract}
SOIL CARBON AND THE MITIGATION OF GLOBAL CLIMATE CHANGE. The soils of the world contain more carbon than the combined total amounts occurring in vegetation and the atmosphere. Hence soils are a major reservoir of carbon in terrestrial ecosystems and an important sink. Recently, emphasis has been placed on the need to sequester carbon from atmospheric carbon dioxide into soil organic matter because of international concerns about greenhouse gas emissions and global climate change. The best strategies to built-up carbon stocks in the soil are basically those that increase the input of organic matter to the soil, and/or decrease the rate of soil organic matter decomposition. Grain crop systems based on soil ploughing and harrowing lead to $\mathrm{CO}_{2}$ emissions combined with tremendous soil losses. In Brazil, no-tillage system was introduced to combat soil erosion by water and this soil management led to the build-up of soil carbon stocks with simultaneous high crop yields. However, the present procedure used to quantify carbon stocks in soils is laborious and of high cost. The use of infrared spectroscopy is very promising as an alternative low-cost method of soil carbon determination.
\end{abstract}

Keywords: soil carbon determination; forest soils; no-tillage.

\section{INTRODUÇÃO}

O sistema climático é interativo e constituído por cinco grandes componentes, atmosfera, hidrosfera, criosfera, supefície terrestre e biosfera, influenciados por vários mecanismos externos no qual o Sol é o mais importante ${ }^{1}$. Além disto, os efeitos diretos das atividades humanas no sistema climático são considerados como mecanismo externo. A atmosfera seca da Terra é consistida principalmente de nitrogênio $\left(\mathrm{N}_{2} ; 78,1 \%\right.$ do volume), oxigênio $\left(\mathrm{O}_{2} ; 20,9 \%\right.$ do volume) e argônio (Ar; $0,93 \%$ do volume). Estes gases possuem limitada interação com a radiação emitida pelo Sol e não interagem com a radiação infravermelha emitida pela Terra. Entretanto, há uma série de gases traços como dióxido de carbono $\left(\mathrm{CO}_{2}\right)$, metano $\left(\mathrm{CH}_{4}\right)$, óxido nitroso $\left(\mathrm{N}_{2} \mathrm{O}\right)$ e ozônio $\left(\mathrm{O}_{3}\right)$ que absorvem e emitem radiação infravermelha. Estes gases traços, também denominados gases de efeito estufa, ocupam menos que $0,1 \%$ do volume da atmosfera e possuem relevante papel no balanço energético da Terra. A atmosfera contém também vapor d'água $\left(\mathrm{H}_{2} \mathrm{O}\right.$; aproximadamente $1 \%$ do volume) que é também um gás de efeito estufa natural. A Terra recebe radiação solar $\left(342 \mathrm{Wm}^{-2}\right)$ e os diferentes gases traços presentes na atmosfera, particularmente na troposfera, absorvem a radiação infravermelha emitida pela Terra e, por sua vez, emitem esta radiação para cima e para baixo. Este processo de absorção e emissão de radiação infravermelha gera aumento na temperatura próxima à superfície da Terra (média de $14{ }^{\circ} \mathrm{C}$ ) resultando num efeito estufa natural e importante para o surgimento e a manutenção da vida no plane$\mathrm{ta}^{1}$. Se não houvesse este efeito estufa natural, a temperatura na superfície da Terra seria $33{ }^{\circ} \mathrm{C}$ mais fria.

Os seres humanos sempre influenciaram o meio ambiente. Entretanto, foi somente após o início da Revolução Industrial, em meados do século XVIII, que o impacto das atividades humanas tomou proporções em escalas continentais e até mesmo globais. Atividades humanas, principalmente aquelas envolvendo a queima de combus-

*e-mail: pedro@cnps.embrapa.br

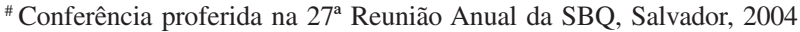

tíveis fósseis para uso industrial e residencial e queima da biomassa (desmatamento seguido de queimadas), produzem gases de efeito estufa que afetam a composição da atmosfera ${ }^{1}$. Embora o gás metano e o óxido nitroso apresentem potencial de aquecimento maior que o gás carbônico $\left(\mathrm{CH}_{4}=23\right.$ vezes o $\mathrm{CO}_{2} \mathrm{e} ; \mathrm{N}_{2} \mathrm{O}=296$ vezes o $\left.\mathrm{CO}_{2}\right)$, o $\mathrm{CO}_{2}$ é emitido em maiores quantidades devido à queima de combustíveis fósseis e desmatamento ou queimada. $\mathrm{O} \mathrm{CH}_{4}$ é relevante em áreas onde se produz arroz inundado (ex. sudoeste da Ásia). O óxido nitroso $\left(\mathrm{N}_{2} \mathrm{O}\right)$ que se acumula na atmosfera provem principalmente da superfície terrestre, mas as incertezas com relação à magnitude das fontes e drenos de $\mathrm{N}_{2} \mathrm{O}$ impedem que se consiga uma quantificação precisa, e os dados atualmente existentes sobre fluxos de $\mathrm{N}_{2} \mathrm{O}$ dos solos e oceanos são insuficientes para quantificá-los em detalhes ${ }^{1,2}$. A mudança no uso da terra, causada pela conversão de florestas em áreas de agricultura ou pecuária, afeta as propriedades físicas e biológicas da superfície terrestre e estes efeitos possuem impacto potencial no clima regional e global ${ }^{1}$.

O objetivo deste trabalho é demonstrar o papel do carbono do solo na mitigação da mudança climática. Ênfase será dada às alterações no uso da terra no Brasil, especialmente a agricultura para produção de grãos (abrangendo 50 milhões de hectares; 1 ha $=10000 \mathrm{~m}^{2}$ ) e como a agricultura conservacionista, ou seja, o sistema de plantio direto, que hoje ocupa 17 milhões de ha no Brasil, pode contribuir eficazmente para o aumento do seqüestro de carbono no solo. Finalmente, no âmbito da Química Ambiental, será feita uma apresentação dos métodos de análise de carbono dos solos no Brasil, seus problemas quanto à quantificação dos estoques de carbono do solo (em megagrama de carbono por ha ou $\mathrm{Mg} \mathrm{Cha}^{-1}$ ) e a necessidade de métodos alternativos.

\section{CICLO DO CARBONO}

Os quatro principais compartimentos de carbono na Terra são: oceanos, atmosfera, formações geológicas contendo carbono fóssil e mineral e ecossistemas terrestres (biota + solo). Na Figura 1 observa-se uma representação esquemática dos diferentes compartimentos de carbono na Terra com seus estoques e respectivos fluxos. 


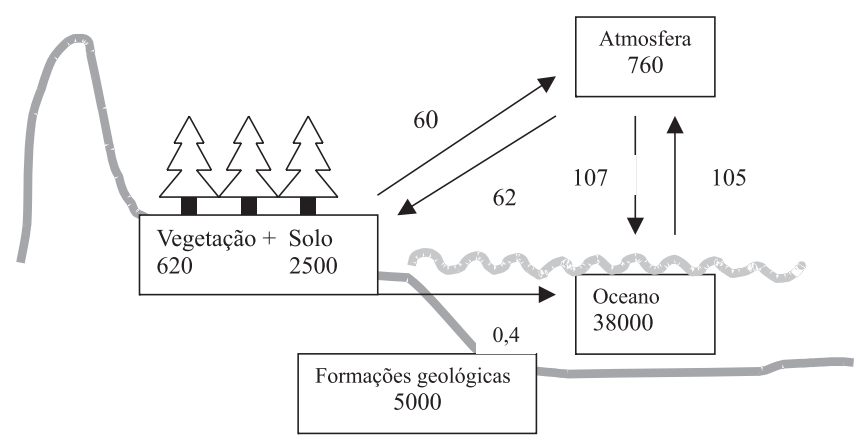

Figura 1. Ciclo global do carbono com estoques (em $\mathrm{Pg} C=10^{15} \mathrm{~g} C$ ) nos diferentes compartimentos da Terra e fluxos de carbono (em $\mathrm{Pg} \mathrm{C}$ ano ${ }^{-1}$ ). Adaptada da ref. 3

Na Figura 1 constata-se que o maior compartimento de carbono na Terra é aquele presente no oceano (38000 Pg C), seguido do compartimento presente nas formações geológicas (5000 Pg C). O carbono das formações geológicas consiste de $4000 \mathrm{Pg} \mathrm{C}$ presentes no carvão, $500 \mathrm{Pg} \mathrm{C}$ no petróleo e $500 \mathrm{Pg}$ C no gás natural. O compartimento de carbono do solo (2500 Pg C) é o maior nos ecossistemas terrestres (aproximadamente 4 vezes o compartimento de $\mathrm{C}$ da vegetação e 3,3 vezes o carbono da atmosfera) e é constituído pelo carbono orgânico (1500 Pg C) e mineral (1000 Pg C). O carbono orgânico representa o equilíbrio entre o carbono adicionado ao solo pela vegetação e o perdido para as águas profundas e, finalmente, para os oceanos via lixiviação como carbono orgânico dissolvido (0,4 Pg C) ou para a atmosfera via atividade microbiana como dióxido de carbono em solos aerados ou metano em solos saturados com água. Entretanto, pouco se sabe sobre valores precisos de perdas de carbono do solo para a atmosfera.

\section{EFEITO ESTUFA ANTROPOGÊNICO E SUAS CONSEQÜÊNCIAS}

O interesse em estudar o ciclo do carbono e o impacto do dióxido de carbono $\left(\mathrm{CO}_{2}\right)$ e do metano $\left(\mathrm{CH}_{4}\right)$ antropogênicos no regime climático, especialmente na temperatura, já havia sido iniciado no século passado ${ }^{4}$. Durante os anos 80 e principalmente desde a primeira conferência do Comitê Assessor Científico do Programa Internacional Geosfera-Biosfera (IGBP), realizada em Estocolmo em 1988, modelos de circulação global e vários trabalhos locais e regionais surgiram com ênfase no efeito estufa de gases traços como $\mathrm{CO}_{2}, \mathrm{CH}_{4} \mathrm{e}$ $\mathrm{N}_{2} \mathrm{O}^{5}$. Naquela época, já havia demonstração sobre as conseqüências do incremento do $\mathrm{CO}_{2}$ na atmosfera no aumento em cerca de $4{ }^{\circ} \mathrm{C}$ na temperatura e na elevação no nível do $\mathrm{mar}^{5}$. Apesar de no final dos anos 90 ainda ter sido controversa a mudança climática causada por gases traços, particularmente pelo $\mathrm{CO}_{2}$, o terceiro relatório do Painel Intergovernamental sobre Mudança Climática ${ }^{6}$, após rigorosa avaliação da qualidade de estudos recentes sobre o tema, destaca que as mudanças no clima ocorrem como resultado tanto da variabilidade interna dentro do sistema climático como também de fatores externos naturais e antropogênicos. A taxa de alteração da concentração de $\mathrm{CO}_{2}$ do período Holoceno (há 10000 anos) foi duas vezes menor que o aumento antropogênico de $\mathrm{CO}_{2}$ desde a Revolução Industrial, iniciada em 1760 na Inglaterra, até os dias atuais ${ }^{7}$. O uso crescente de combustíveis fósseis e as mudanças em larga escala do uso das terras resultaram no aumento das concentrações de gases de efeito estufa na atmosfera, afetando o clima global ${ }^{1}$. Entre 1861 e 2000 a temperatura média global aumentou $0,6^{\circ} \mathrm{C}$. As precipitações pluviométricas têm se alterado com chuvas mais torrenciais e o fenômeno "El Niño" tem se tornado mais freqüente, persistente e intenso ${ }^{8}$. Num cenário de referência tradicional (do inglês: "business as usual"), a temperatura média da Terra aumentará entre 1,4 e $5,8^{\circ} \mathrm{C}$ até 2100 , com as áreas terrestres se aquecendo mais que os oceanos e causando uma elevação no nível do mar entre 9,0 e 88,0 cm. Há consenso na comunidade científica internacional sobre o seguinte aspecto: se não houver nenhuma ação mitigadora, os efeitos da mudança climática serão devastadores, onde ocorrerá aumento na incidência de temporais intercalados por anos de seca prolongada ${ }^{8,9}$. A agricultura brasileira será seriamente afetada pelo aquecimento global ${ }^{10}$. Assim, a mudança climática global poderá ser o problema ambiental mais crítico e complexo a ser enfrentado pela humanidade ao longo do século $\mathrm{XXI}^{11}$.

\section{O CARBONO DO SOLO E A MUDANÇA CLIMÁTICA GLOBAL}

O Protocolo de Quioto, estabelecido em dezembro de 1997 durante a Terceira Sessão da Conferência das Partes (COP 3) da Convenção Quadro da ONU para a Mudança Climática (UNFCCC), definiu metas de redução nas emissões de gases de efeito estufa para a atmosfera. Entre 2008 e 2012, a Europa deverá reduzir as emissões em 8\% abaixo dos níveis de 1990. Os Estados Unidos e o Japão deverão reduzir em 7 e $6 \%$, respectivamente. O objetivo da UNFCCC é estabilizar as concentrações de gases de efeito estufa na atmosfera, a um nível que permita limitar os impactos adversos no clima do planeta.

Diversas instituições de pesquisa públicas e privadas vêm desenvolvendo tecnologias para mitigar as concentrações de $\mathrm{CO}_{2}$ na atmosfera. As opções incluem: 1 . separação e captura de $\mathrm{CO}_{2}$ a partir de sistemas energéticos e 2. seqüestro de carbono nos oceanos, ecossistemas terrestres e formações geológicas. Um aspecto importante a se considerar é até que ponto as medidas técnicas podem ser efetivas em períodos de crescimento econômico, associados com altas demandas por combustíveis fósseis pelo setor industrial e de transportes ${ }^{11}$. E se estas medidas, sozinhas, podem reduzir adequadamente os níveis de $\mathrm{CO}_{2}$ atuais como preconizado pelos governos.

Os ecossistemas terrestres que compreendem a vegetação e o solo são considerados atualmente como um grande sumidouro (do inglês "sink") de carbono, especialmente os solos (Figura 1). Há várias maneiras pelas quais o manejo apropriado da biosfera terrestre, particularmente do solo, possa resultar em significativa redução no aumento dos gases de efeito estufa. Conforme demonstrado na Tabela 1, os solos das diferentes florestas no mundo apresentam maior estoque de carbono que a vegetação, especialmente os solos de floresta boreal (regiões geladas) e os campos das regiões temperadas (ex. pradarias nos EUA e pampas da América do Sul).

A agricultura introduzida após desmatamento tem resultado em fortes impactos, aumentando a emissão de gases de efeito estufa para

Tabela 1. Estoque global de carbono na vegetação e no solo (prof. $100 \mathrm{~cm}$ ). Adaptada das refs. 2 e 12

\begin{tabular}{lcccc}
\hline Bioma & Área & \multicolumn{4}{c}{ Estoques de Carbono (Gt de C) } \\
& $\left(10^{6} \mathrm{~km}^{2}\right)$ & Vegetação & Solos & Total \\
\hline Floresta Tropical & 17,6 & 212 & 216 & 428 \\
Floresta Temperada & 10,4 & 59 & 100 & 159 \\
Floresta Boreal & 13,7 & 88 & 471 & 559 \\
Savanas Tropicais & 22,5 & 66 & 264 & 330 \\
Campos Temperados & 12,5 & 9 & 295 & 304 \\
Desertos e semidesertos & 45,5 & 8 & 191 & 199 \\
Tundra & 9,5 & 6 & 121 & 127 \\
Pântanos & 3,5 & 15 & 225 & 240 \\
Terras agrícolas & 16,0 & 3 & 128 & 131 \\
TOTAL & 151,2 & 466 & 2011 & 2477 \\
\hline
\end{tabular}


a atmosfera. Já em 1864 é possível encontrar relatos científicos sobre as conseqüências negativas da atividade antrópica na paisagem terrestre e, mais recentemente, em 1956, foi constatado que uma das mudanças globais mais incontestáveis nos últimos três séculos foi a ação direta do homem e mudança da cobertura das terras ${ }^{13}$. A expansão da agricultura através da derrubada de florestas durante os últimos 140 anos levou a uma liberação líquida de $121 \mathrm{Gt}$ de carbono para a atmosfera $(1 \mathrm{Gt}=1.000 .000 .000 \mathrm{t})$ e o Brasil é o maior responsável ("single contributor") pela emissão de gases de efeito estufa pela mudança no uso da terra ${ }^{2,14}$. A maior parte dos desmatamentos ocorridos na Amazônia Legal (que abrange os Estados do Amazonas, Acre, Roraima, Rondônia, Pará, Amapá, Mato Grosso, Tocantins e parte do Maranhão) são devidos à conversão da floresta em pastagens ${ }^{15}$. Em 1994, o desmatamento na Amazônia Legal alcançou 470 milhões de ha $\left(470 \times 10^{3} \mathrm{~km}^{2}\right)$. Deste total, aproximadamente $45 \%$ ficaram ocupados pela bovinocultura de corte (produção de carne bovina) a partir da derrubada da floresta tropical, $28 \%$ ficaram ocupados por floresta secundária após abandono dos pastos pós-1970 e $2 \%$ ficaram ocupados por pastagens degradadas ${ }^{16}$. A área restante ficou ocupada pela agricultura (5\%), floresta secundária oriunda de agricultura abandonada (2\%) e floresta secundária anterior a 1970 (17\%). Considerando uma paisagem dominada por pastagem e floresta secundária oriunda de pastagens abandonadas, a média líquida de carbono perdido do solo foi estimada em 11,7 X $10^{6} \mathrm{Mg} \mathrm{C}$ para $1,38 \times 10^{6}$ ha desmatados em 1990. Sem dúvida que, atualmente, a abertura de novas áreas de floresta para implantar sistemas agropecuários não é desejável. Isto devido a dois momentos de forte emissão de $\mathrm{CO}_{2}$ para a atmosfera: um no desmatamento seguido da queimada e outro, com o preparo do solo pela aração seguida de sucessivas gradagens niveladoras para adequar a superfície do solo para receber as sementes. O preparo do solo pela aração pode resultar em até $81,3 \mathrm{~g} \mathrm{CO}_{2} \mathrm{~m}^{-2}$ emitidos para a atmosfera num período de $5 \mathrm{~h}^{17}$. O problema deste tipo de agricultura convencional, embasada na operação de preparo do solo pela aração seguida de diversas gradagens niveladoras, se agrava pelo fato desta operação ser realizada, no mínimo, duas vezes ao ano na agricultura brasileira. Além disto, a aração do solo seguida de várias gradagens predispõe o solo à erosão hídrica, que contribui para o agravamento das emissões de $\mathrm{CO}_{2}$ para a atmosfera. Globalmente, a erosão causada pelas chuvas é responsável por emissão líquida anual de aproximadamente $1 \mathrm{Gt}^{18}$. Nos anos 70, devido aos sérios problemas de degradação das terras pela erosão, foi introduzido no Sul do Brasil o sistema plantio direto, que consistia em instalar lavouras de milho, trigo e soja sem necessidade de preparo do solo (ex. aração seguida de gradagens niveladoras). Os agricultores, motivados pelos menores riscos envolvidos no plantio direto em relação à agricultura convencional, adotaram o novo manejo do solo que combate eficazmente a erosão e, hoje, no Brasil, ocupa atualmente 17 milhões de ha (40\% da área sob agricultura de plantas anuais $)^{19}$.

\section{USO AGRÍCOLA DO SOLO E SIMULTÂNEO SEQÜESTRO DE CARBONO}

Durante reunião do $\mathrm{IPCC}^{20}$, a possibilidade de se utilizar práticas agrícolas conservacionistas como o sistema plantio direto para mitigar o aumento de $\mathrm{CO}_{2}$ na atmosfera pelo seqüestro de carbono pelo solo obteve consenso internacional. A idéia contida no consenso foi que promovendo a adoção de práticas agrícolas com conservação do solo seria possível não apenas aumentar a produtividade agrícola como também transformar os solos agrícolas em drenos ou sumidouros de $\mathrm{CO}_{2}$ atmosférico. O sistema plantio direto (SPD) é um exemplo de uso da terra para a agricultura nas regiões tropicais úmidas e sub-tropicais que propicia segurança alimentar com baixo im- pacto ambiental, principalmente quanto à erosão (perda de solo) e favorecendo o seqüestro de carbono no solo ${ }^{21}$. Seqüestro de carbono no solo significa transformar o carbono presente na atmosfera (na forma de $\mathrm{CO}_{2}$ ) em carbono estocado no solo, compondo a matéria orgânica do solo.

A quantificação do estoque de carbono no solo é feita em base volumétrica para uma determinada profundidade do solo e normalmente é expressa em $\mathrm{Mg} \mathrm{C}$ hectare $^{-1}$, sendo $1 \mathrm{Mg}=1$ megagrama ou 1 tonelada métrica. Vários estudos demonstraram a eficácia do SPD no sequiestro de carbono em solos agrícolas brasileiros, principalmente para as camadas superficiais do solo $(0-20 \mathrm{~cm})$, com incrementos de 5,2 a $8,5 \mathrm{Mg} \mathrm{C}^{-1}$ superiores ao solo sob preparo convencional (aração e gradagens) ${ }^{19,22}$. Numa avaliação das mudanças no estoque de carbono de solo do Rio Grande do Sul com 13 anos de preparo convencional ou plantio direto (Figura 2), constatou-se, a uma profundidade de $100 \mathrm{~cm}$, que o estoque de carbono orgânico do solo sob SPD, com 179 $\mathrm{Mg} \mathrm{C} \mathrm{ha-1}$, era 8,5\% superior ao solo sob preparo convencional, com $165 \mathrm{Mg} \mathrm{C} \mathrm{ha}^{-1}$, e 4,7\% superior ao solo sob floresta secundária, com $171 \mathrm{Mg} \mathrm{C} \mathrm{ha}^{-1}$. A eficácia no acúmulo de carbono do solo pelo SPD é aumentada quando, após o cultivo da cultura principal (ex. soja), introduz-se na sequiência de cultivo uma planta leguminosa (ex. tremoço), que fixa nitrogênio da atmosfera no solo pela associação com bactérias. Assim, observa-se na Figura 2 que tanto o SPD como o preparo convencional sob Rotação, ou seja, sob uma série de cultivos intercalados envolvendo gramíneas (ex. milho, aveia) e leguminosas (ex. tremoço), maiores estoques de carbono do solo que sob Sucessão (série de cultivos intercalados, envolvendo apenas culturas de interesse econômico (ex. soja e trigo).

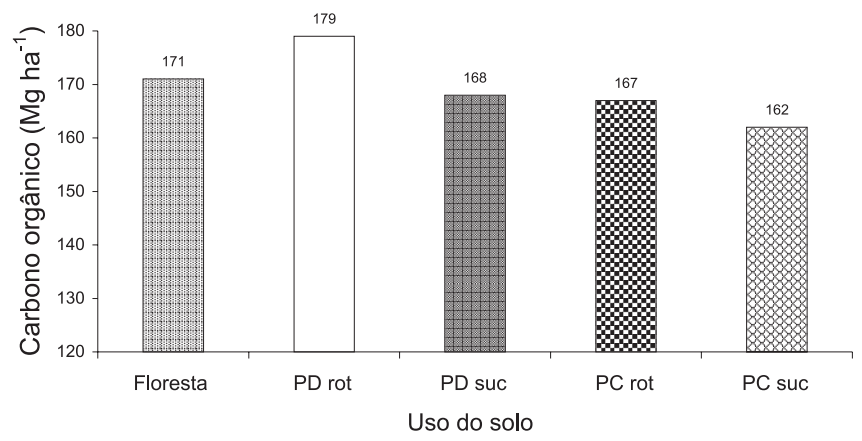

Figura 2. Estoque de carbono orgânico a $100 \mathrm{~cm}$ de profundidade de solo sob floresta e após 13 anos sob cultivo de grãos em sistema plantio direto $(P D)$ e convencional com aração e gradagens $(P C)$ em sucessão (suc; trigosoja) e rotação (rot; trigo-soja-aveia-soja-ervilhaca-milho). Adaptada da ref. 23

\section{PROCESSOS E FATORES QUE REGULAM A DINÂMICA DO CARBONO DO SOLO}

O carbono orgânico do solo está presente na matéria orgânica viva, que corresponde a menos de $4 \%$ do carbono orgânico total do solo e na matéria orgânica morta, que corresponde à maior parte do carbono orgânico total do solo (cerca de $98 \%)^{24}$. O carbono da matéria orgânica viva (CMOV) subdivide-se no carbono presente nos microrganismos (60-80\% do CMOV), consistido principalmente de fungos e bactérias, nos macrorganismos (15-30\% do CMOV) consistido, por exemplo, por minhocas, ácaros e térmitas terrestres e, finalmente, nas raízes (5- 10\% do CMOV). Quanto ao carbono da matéria orgânica morta (CMOM), o carbono se subdivide na matéria macrorgânica ou seja, resíduos vegetais recém adicionados ao solo e no húmus (80-90\% do CMOM), que consiste de substâncias nãohúmicas (30\% do carbono do húmus) representadas pelos ácidos 
orgânicos de baixo peso molecular (ex. ácido cítrico, ácido ftálico, ácido malônico) e substâncias húmicas (70\% do carbono do húmus) representadas pelos ácidos húmicos, ácidos fúlvicos e huminas. Quanto ao carbono inorgânico representado pelos carbonatos no solo, devido à grande maioria dos solos brasileiros apresentarem reação ácida $\left(\mathrm{pH}_{\text {agua }}<6,0\right)$ sua participação é insignificante, estando presente em ambientes restritos como os solos da região semi-árida do Brasil. Apesar do CMOV estar presente em proporção bem menor que o CMOM as importâncias se igualam, pois os micro e macrorganismos, pelas suas atividades no solo, se constituem num dos principais fatores responsáveis pelas transformações do CMOM, resultando em acúmulo ou perdas (na forma de $\mathrm{CO}_{2}$ ) de carbono orgânico do solo.

O estoque de carbono de um solo sob vegetação natural representa o balanço dinâmico entre a adição de material vegetal morto e a perda pela decomposição ou mineralização ${ }^{25}$. As taxas de adição e a qualidade do carbono da vegetação dependem muito do clima (principalmente temperatura do ar e chuvas), do tipo de vegetação (gramíneas decompõem-se mais lentamente que plantas leguminosas) e da fertilidade do solo (solos férteis resultam em plantas maiores que contêm, por sua vez, mais carbono a ser depositado no solo $)^{11}$. Os resíduos de plantas (ex. folhas, galhos, frutos) que caem sobre o solo são gradualmente alterados por meio da fragmentação física, interações entre a fauna do solo e microrganismos e formação de húmus. Os processos de decomposição e taxas de transformação (do inglês "turnover rate" = quantidade de carbono em determinado compartimento do solo dividido pela taxa de adição anual de carbono para este compartimento) são fortemente influenciados pelo clima, tipo e qualidade da matéria orgânica, associações químicas e físicoquímicas da matéria orgânica com os componentes minerais do solo e pela localização da matéria orgânica no solo ${ }^{11}$. Sabe-se que os componentes de uma planta morta são sujeitos ao ataque de macrorganismos (ex. coró, térmitas do solo, minhocas) e, em seguida ou simultaneamente, sofrem decomposição microbiana no solo. Sabe-se também que diferentes componentes das plantas se decompõem a diferentes taxas. Por exemplo, açúcares simples e proteínas são decompostos rapidamente em questão de horas ou alguns dias. Por outro lado, ligninas e suberinas demandam muito mais tempo para serem decompostas ${ }^{26}$. A taxa de mineralização da matéria orgânica em regiões temperadas (ex. Europa Central) é de aproximadamente $2 \%$ e nos trópicos úmidos (ex. Amazônia) é de 4 a $5 \%$. Por outro lado, a produção de biomassa, ou seja, de vegetação, é maior nos trópicos úmidos.

Os três principais processos responsáveis pelo seqüestro de carbono nos solos são a humificação, agregação e sedimentação. Ao mesmo tempo, os processos responsáveis pelas perdas de carbono no solo são a erosão, decomposição, volatilização e lixiviação (Figura 3).

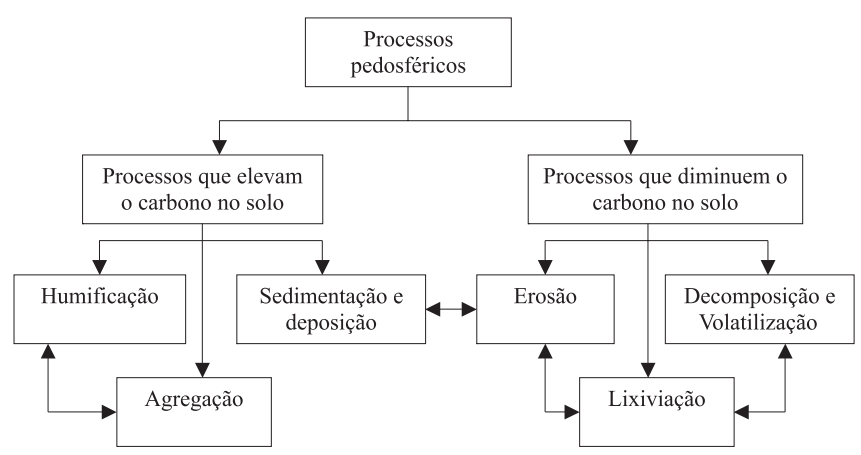

Figura 3. Principais processos no solo que influenciam o conteúdo de carbono no solo. Adaptada da ref. 27
A agregação do solo (união de partículas de areia, silte e argila para formar pequenos torrões estáveis ao impacto da gota de chuva), realizada pela ação de hifas de fungos e substâncias orgânicas provenientes das raízes das plantas ou dos produtos da decomposição da matéria orgânica pelos microrganismos, vem sendo enfatizada como um dos fatores mais importantes para o seqüestro de carbono no solo $^{27}$. Em solos brasileiros também foi observado que a adoção do plantio direto favoreceu a agregação do solo aumentando, conseqüentemente, o acúmulo de carbono ${ }^{28}$.

\section{QUANTIFICAÇÃO DE ESTOQUES DE CARBONO DOS SOLOS}

Conforme exposto anteriormente, o carbono do solo se encontra em diferentes compartimentos com diferentes taxas de transformação. É importante mencionar que o Protocolo de Quioto está essencialmente interessado nos fluxos de carbono, ou seja, mais nas mudanças nos níveis de carbono que nos teores ou estoques de carbono num determinado compartimento do solo ${ }^{26}$. Entretanto, a avaliação dos diferentes compartimentos de carbono no solo e suas dinâmicas são imprescidíveis para a identificação de usos e manejos do solo que promovam o seqüestro de carbono.

A quantificação de estoque de carbono do solo consiste essencialmente em dois passos: 1. amostragem de solo no campo para análise de carbono total e densidade do solo; 2 . determinação de carbono total em amostras e quantificação dos estoques em $\mathrm{Mg} \mathrm{C} \mathrm{ha-1}$. A densidade do solo $\left(\rho, \mathrm{g} \mathrm{cm}^{-3}\right)$, antigamente denominada de densidade aparente ou global do solo, corresponde à massa de solo seco por unidade de volume, ou seja, o volume do solo ao natural, incluindo os espaços porosos ${ }^{29}$. A coleta de amostras de solos no campo e determinação da densidade do solo é essencial para se calcular a massa ou o estoque de carbono total do solo a partir da concentração de carbono total do solo ( $\mathrm{C} ; \mathrm{g} \mathrm{C} \mathrm{kg}^{-1}$ solo). Na quantificação do estoque de carbono há necessidade de se estabelecer a profundidade do solo a que se refere o estoque. Assim, ao se coletar as amostras de solos para a determinação da densidade e da concentração de carbono total do solo, há necessidade de anotar a profundidade da camada de solo em que as amostras foram coletadas. $\mathrm{O}$ cálculo do estoque de carbono (EC; $\mathrm{Mg} \mathrm{C} \mathrm{ha}^{-1}$ ) para uma determinada profundidade (p, $\mathrm{cm})$ dá-se da seguinte maneira:

$\mathrm{EC}=\mathrm{C} \times \rho \times \mathrm{p} / 10$

Embora a determinação da densidade do solo seja uma tarefa rápida, a coleta no campo é passível de erros e normalmente é mais laboriosa com o aumento da profundidade do solo que a coleta de amostras para a determinação de carbono do solo. Isto porque há a necessidade de se abrir uma trincheira ou perfil de solo até, pelo menos, $10 \mathrm{~cm}$ abaixo da última camada de solo que normalmente atinge $60 \mathrm{~cm}$. Já há constatação no Brasil de que o carbono orgânico de um Latossolo Vermelho, incorporado juntamente com os resíduos de planta pela aração a $20 \mathrm{~cm}$, se movimenta $10 \mathrm{~cm}$ abaixo da profundidade de $\operatorname{aração~}^{30}$. Assim, as coletas de amostras para a determinação da concentração de carbono $(C)$ e da densidade do solo $(\rho)$ podem ser feitas por camadas de solos a seguir: 0-5, 5-10, 10-20, 2030, 30-40 e 40-60 cm. Trata-se de uma sugestão para Latossolos e Argissolos que cobrem 59\% da área do Brasil (aproximadamente 5 milhões de ha) ${ }^{31}$. O teor de carbono total do solo diminui exponencialmente com a profundidade ${ }^{19,23,32}$. Em geral, 39-70\% do carbono orgânico total na camada de $0-100 \mathrm{~cm}$ de solo mineral está presente nos primeiros $30 \mathrm{~cm}$ e $58-81 \%$ nos primeiros $50 \mathrm{~cm}^{33}$. Perdas ou aportes de carbono do solo são maiores no horizonte superficial $(0-15 \mathrm{~cm})$, que deve ser amostrado mais freqüentemente ${ }^{34}$. En- 
tretanto, havendo mudanças no uso e manejo a amostragem deve ser feita a profundidades maiores, pois o acúmulo de carbono na superfície pode ser balanceado por perdas em profundidade ${ }^{2}$. Não seria prático, todavia, definir uma profundidade para todos os solos, onde o carbono seria analisado. A profundidade de amostragem deve ser abaixo da profundidade onde se espera uma mudança significativa no teor de carbono ${ }^{2}$.

Há também a questão da variabilidade espacial do estoque de carbono. Numa lavoura de 13 ha de produção de grãos (milho, soja e trigo) em plantio direto em Carambeí, Paraná, constatou-se uma variação de 26 a $62 \mathrm{Mg} \mathrm{C}^{-1}$ para a profundidade de $0-20 \mathrm{~cm}^{35}$.

A medição da densidade do solo é imprescindível em qualquer situação, pois somente através desta medida será possível quantificar a massa de solo presente em determinada profundidade. Há solos, todavia, em que tal recomendação de amostragem de solos deva ser considerada com cuidado. Os Espodossolos, por exemplo, apresentam os maiores teores de carbono a $400 \mathrm{~cm}$ de profundidade. Estes solos têm representatividade baixa no país $(<2 \%$ da área total do Brasil), mas podem ter significância no uso agrícola de determinada região. Especial atenção deve ser dada aos Organossolos (popularmente denominados de solos turfosos). Têm pouca abrangência nacional ( $<1 \%$ da área total do Brasil), mas podem apresentar elevado teor de carbono total (> $200 \mathrm{~g} \mathrm{C} \mathrm{kg}^{-1}$ solo) por vários metros de profundidade. Estes solos são muito sensíveis a grandes perdas de carbono orgânico pelas mudanças no regime de drenagem ou temperatura do solo.

Após a coleta das amostras no campo, estas são transferidas para laboratório onde são preparadas (secas ao ar, moídas e passadas em peneira de $2 \mathrm{~mm}$ ) para a quantificação ou determinação de carbono. As amostras para a densidade do solo são igualmente transferidas para o laboratório, onde são secas a $105^{\circ} \mathrm{C}$ até peso constante para a determinação da massa de solo. A determinação de carbono no Brasil é feita comumente pelo método da combustão via úmida, baseado na oxidação da matéria orgânica a $\mathrm{CO}_{2}$ por íons dicromato em meio fortemente ácido ${ }^{36}$. Utiliza-se um oxidante forte (dicromato de potássio) numa solução ácida, para a oxidação da matéria orgânica. O teor de carbono é obtido indiretamente pela diferença entre a quantidade total de redutor (dicromato) utilizada e a quantidade restante após a oxidação do carbono. Embora simples e de baixo custo, o método apresenta problemas quanto à acurácia, devido à necessidade de fatores de correção para compensar a oxidação parcial e, também, quanto à lentidão e ao grande espaço que ocupa nos laborató$\operatorname{rios}^{37}$. Finalmente, a determinação do carbono por combustão via úmida gera problemas no meio ambiente pela produção de rejeitos laboratoriais de difícil descarte (ex. soluções ácidas contendo cromo). A determinação de carbono total por combustão via seca utilizando-se modernos equipamentos vem sendo considerada como referência pela precisão analítica (2-3\%). Todavia, a aquisição e manutenção destes equipamentos são de custos altos para a grande maioria dos laboratórios no Brasil. Nos últimos anos, o advento e aperfeiçoamento das técnicas espectroscópicas para estudos da matéria orgânica do solo vêm demonstrando o forte potencial da espectroscopia como procedimento alternativo na determinação do carbono total do solo ${ }^{38}$. Dentre as diferentes técnicas, a espectroscopia de reflectância difusa de médio-infravermelho ou, simplesmente, infravermelho médio ${ }^{39}$ e a fotoluminescência ${ }^{40}$ são as técnicas mais promissoras para a determinação do teor total de carbono do solo.

Métodos alternativos para a determinação da densidade do solo ainda carecem de melhor desenvolvimento. Há forte demanda para o desenvolvimento de sensores para a determinação da concentração de carbono total e da densidade do solo in situ e em tempo real, de modo a se obter o mapa do estoque de carbono numa área imediatamente após a medição no campo.

\section{CONSIDERAÇÕES FINAIS}

As maiores reservas de carbono encontram-se nos oceanos e, no ecossistema terrestre, a maior reserva de carbono encontra-se no solo, principalmente nas regiões geladas e nas pradarias ou campos de regiões temperadas. Há aproximadamente 200 anos o homem vem interferindo massivamente no fluxo global de carbono e a agricultura convencional, embasada no uso de arados e grades para o preparo do solo para a semeadura, contribui para as perdas de carbono do solo. O plantio direto é um sistema de produção agrícola que reverte esta situação, combatendo eficazmente a erosão e contribuindo significativamente para o seqüestro de carbono no solo.

Diferente das reservas de carbono fóssil, o carbono do solo não é permanente e pode, a curto ou longo prazo, se transferir para a atmosfera. Assim, não pode compensar na totalidade as emissões oriundas da queima de combustíveis fósseis. Pelo solo ser o maior compartimento de carbono nos ecossistemas terrestres e poder estocar carbono pela agricultura conservacionista (ex. sistema plantio direto), a humanidade pode, com o uso adequado do solo, retardar ou amenizar os impactos negativos da mudança climática global.

Procedimentos analíticos usuais para a quantificação do estoque de carbono no solo são laboriosos, pouco precisos e geram impactos negativos no meio ambiente. Há necessidade de se desenvolver métodos analíticos ágeis, de baixo custo, exatos, precisos e portáteis para a quantificação in situ e em tempo real do estoque de carbono no solo. As técnicas de infravermelho próximo para a determinação da concentração de carbono no solo ( $\mathrm{em} \mathrm{g} \mathrm{C} \mathrm{kg}^{-1}$ ) e o uso de funções de pedotransferência para as estimativas de densidade do solo apresentam grande potencial como métodos alternativos.

\section{REFERÊNCIAS}

1. Baede,A. P. M.; Ahlonsou, E.; Ding, Y.; Schimel, D. Em Climate Change 2001: The Scientific Basis; Houghton, J. T.; Ding, Y.; Griggs, D. J.; Noguer, M.; Van der Linden, P. J.; Dai, X.; Maskell, K.; Johnson, C. A., eds.; Cambridge University Press: Cambridge, 2001, chap. 1.

2. Watson, R. T.; Noble, I. R.; Bolin, B.; Ravindranath, N. H.; Verardo, D. J.; Dokken, D. J.; Land Use, Land-Use Change and Forestry: A Special Report of the IPCC, Cambridge University Press: Cambridge, 2000.

3. Lal, R.; Global Climate Newsletter 1999, 37, 4.

4. Callendar, G. S.; Q. J. R. Meteorol. Soc. 1938, 64, 223.

5. Scharpenseel, H. W.; Geoderma 1997, 79, 1.

6. IPCC - Intergovernmental Panel on Climate Change; Climate Change 2001: Synthesis Report - A contribution of working groups I, II, and III to the Third Assessment Report of the Intergovernmental Panel on Climate Change, Cambridge University Press: Cambridge, 2001.

7. Indermühle, A.; Stocker, T. F.; Joos, F.; Fischer, H.; Smith, H. J.; Wahklen, M.; Deck, B.; Mastoianni, D.; Tschumi, J.; Blunier, T.; Meyer, R.; Stauffer, B.; Nature 1999, 398, 121.

8. Garrity, D.; Fisher, M.; Proceedings of the Workshop on Tropical Agriculture in Transition: Opportunities for Mitigating Greenhouse Gas Emissions, Center for Development Research: Bonn, Germany, 2001.

9. Fearnside, P. M.; Ecological Economics 2001, 39, 167.

10. Canziani, O. F.; Díaz, S.; Calvo, E.; Campos, M.; Carcavallo, R.; Cerri, C. C.; Gay-Garcia, C.; Mata, L. J.; Saizar, A.; Aceituno, P.; Andressen, R.; Barros, V.; Cbido, M.; Fuenzalida-Pince, H.; Funes, G.; Galvão, C.; Moreno, A. R.; Vargas, W. M.; Viglizao, E. F.; De Zuviria, M. Em The Regional Impact of Climate Change: An Assessment of Vulnerability; Watson, R. T.; Zinyowera, M. C.; Moos, R. H., eds.; Cambridge University Press: Cambridge, 1998.

11. Batjes, N.; Management Options for Reducing CO2-Concentrations in the Atmosphere by Increasing Carbon Sequestration in the Soil, International Soil Reference and Information Centre: Wageningen. 1999.

12. Wissenschaftlicher Beirat der Bundesregierung - Globale Umweltveraenderungen; Die Anrechnung biologischer Quellen und Senken im Kyoto-Protokoll: Fortschritt oder Rueckschlag fuer den globalen Umweltschutz, WBGU: Bremerhaven, 1998.

13. Ramankutty, N. K. K.; Goldwijk, K. K.; Leemans, R.; Foley, J.; Oldfield, F.; Global Change Newsletter 2001, 47, 17

14. Fearnside, P. M.; Ecol. Econ. 2001, 39, 167. 
15. Fearnside, P. M.; Imbrozio Barbosa, R.; For. Ecol. Manag. 1998, 108, 147.

16. Fearnside, P. M. R.; For. Ecol. Manag. 1996, 80, 21.

17. Reicosky, D. C.; Nutr. Cycl. Agroec. 1997, 49, 273.

18. Lal, R.; Griffin, M.; Apt, J.; Lave, L.; Granger Morgan, M.; Nature 2004, 304, 393.

19. Machado, P. L. O. A.; Silva, C. A.; Nutr. Cycl. Agroec. 2001, 61, 119.

20. IPCC - Intergovernmental Panel on Climate Change; Climate Change 1992: The Suplementary Report to the IPCC Scientific Assessment, Cambridge University Press: Cambridge, 1992.

21. Machado, P. L. O. A.; Freitas, P. L. Em Sustainable Agriculture and the International Rice-Wheat System; Lal, R.; Hobbs, P. R.; Uphoff, N.; Hansen, D. O., eds.; Marcel Dekker Inc.: New York, 2004, cap. 18.

22. Bayer, C.; Bertol, I.; R. Bras. Ci. Solo 1999, 23, 687.

23. Sisti, C. P. J.; Santos, H. P.; Kohhann, R.; Alves, B. J. R.; Urquiaga, S.; Boddey, R. M.; Soil Till. Res. 2004, 76, 39.

24. Theng, B. K. G. Em Soil Structure and Aggregate Stability; Rengasamy, P., ed.; Seminar Proceedings. Institute of Irrigation and Salinity Research: Tatura, Australia, 1987.

25. Scholes, M.; Powlson, D.; Tian, G.; Geoderma 1997, 79, 25.

26. Swift, R. S.; Soil Sci. 2001, 166, 858.

27. Lal, R.; Kimble, J.; Follett, R. F. Em Methods for Assessment of Soil Degradation; Lal, R.; Blum, W. H.; Valentine, C.; Stewart, B. A., eds.; CRC Press: Boca Raton, 1997. cap. 1.

28. Madari, B.; Machado, P. L. O. A.; Torres, E.; Andrade, A. G.; Valencia, L. I.; Soil Till. Res., no prelo. http://www.sciencedirect.com/science.

29. Curi, N.; Larach, J. O. I.; Kämpf, N.; Moniz, A. C.; Fontes, L. E. F.; Vocabulário de Ciência do Solo, Sociedade Brasileira de Ciência do Solo: Campinas, 1993.
30. Machado, P. L. O. A.; Sohi, S. P.; Gaunt, J. L.; Soil Use Manag. 2003, 19, 250

31. Coelho, M. R.; Santos, H. G.; Silva, E. F.; Aglio, M. L. D. Em Uso Agrícola dos Solos Brasileiros; Manzatto, C. V.; Freitas Junior, E.; Peres, J. R. R., eds.; Embrapa Solos: Rio de Janeiro, 2002, cap. 1.

32. Nakane, K.; Jpn. J. Ecol. 1976, 26, 171.

33. Batjes, N.; Eur. J. Soil Sci. 1996, 47, 151.

34. Richter, D. D.; Marlewitz, D.; Trumbore, S. E.; Wells, C. G.; Nature 1999, 400, 56.

35. Machado, P. L. O. A.; Bernardi, A. C. C.; Valencia, L. I. O.; Silva, C. A.; Andrade, A. G.; Madari, B.; Meirelles, M. S. P.; Boletim de Pesquisa e Desenvolvimento 2003, 25.

36. Embrapa - Centro Nacional de Pesquisa de Solos; Manual de Métodos de Análise de Solo, Centro Nacional de Pesquisa de Solos: Rio de Janeiro, 1997.

37. Metson, A. J.; Blakemore, L. C.; Rhoades, D. A.; New Zeal. J. Soil Sci. 2002, 167, 281

38. Madari, B.; Micheli, E.; Czinkota, I.; Johnston, C. T.; Graveel, J. G.; Agrokémia és Talajtan 1998, 47, 128; Madari, B.; Micheli, E.; Johnston, C. T.; Graveel, J. G.; Czinkota, I.; Agrokémia és Talajtan 1997, 46, 127; McCarty, G. W.; Reeves, J. B. Em Assessment Methods for Soil Carbon; Lal, R.; Kimble, J. M.; Follet, R. F.; Stewart, B. A., eds.; Lewis Publishers: Boca Raton, 2001; Schnitzer, M.; Can. J. Soil Sci. 2001, 81, 249.

39. Mimmo, T.; Reeves, J. B.; McCarty, G. W.; Galleti, G.; Soil Sci. 2002, 167, 281 ;

40. Milori, D. M. B. P.; Martin-Neto, L.; Bayer, C.; Bagnato, V. S.; Resumo do $4^{\circ}$ Encontro Brasileiro de Substâncias Húmicas, Viçosa, Brasil, 2001. 